\title{
Producto de acumulación lipídica está asociado con glucemia en estudiantes universitarias
}

\author{
Lipid accumulation product is \\ associated with blood glucose in \\ female university students
}

\begin{abstract}
The use of anthropometric indexes, to follow up cardiovascular and metabolic risk factors, has been the focus of several studies during the last years. The Lipid Accumulation Product (LAP) innovates in combining waist circumference (WC), an anthropometric parameter, with fasting triglycerides, a biochemical parameter: the. The LAP was proposed in 2005 by Kahn as a better index than the Body Mass Index (BMI) to predict cardiovascular risk. The few studies published do not present LAP in young female population. For this reason, our study analyzed the association between LAP and fasting glycemia in female university students. A significant positive correlation was found, confirming previous studies with different populations.

Key words: Glycemia, blood glucose, lipid accumulation product, university students.
\end{abstract}

Lia Silveira Adriano (1) Fernanda Maria Machado Maia (2) Antonio Augusto Ferreira Carioca (3) Nadia Tavares Soares (2)

(1) Departamento de Nutrición, Centro de Ciencias de la Salud, FUNCAP beca.
Universidad del Estado de Ceará (UECE), Fortaleza, Ceará, Brasil.
(2) Departamento de Nutrición, Centro de Ciencias de la Salud.
Fortaleza, Ceará, Brasil.
(3) Universidad de São Paulo, Escuela de Salud Pública, Departamento de Nutrición.
São Paulo, São Paulo, Brasil.
Dirigir la correspondência a:
Profesora
Nadia Tavares Soares
Centro de Ciencias de la Salud
Departamento de Nutrición
Universidad del Estado de Ceará.
Fortaleza, Ceará, Brasil.
E-mail: nadiatsoares@gmail.com

Este trabajo fue recibido el 31 de Enero de 2014 y aceptado para ser publicado el 28 de Junio de 2014.

sedentarism and high fat diets (5). Even though, there are few studies published with young populations.

The present study aims to investigate the association of LAP with glucose blood levels in young female university students.

\section{SUBJECTS AND METHODS}

In 2010, a hundred nutrition students were invited to participate in the study. This invitation was alleatory and estratified, including students from the first to the seventh semester. The study was finished with ninety students. Mean age was 22.2 (3.6) years of age. The size of the sample calculated was of 80 students considering data from Xia et al. (6), alpha $=0.05$, bilateral and beta $=0.10$.

This study was approved by the Ethics and Research Committee of the university where the data were collected with the process number 08628340-5 and the participants signed a term or free and informed consent.

Fasting glucose and triglyceride blood levels were measured and the anthropometric parameter waist circumference was verified. Other life style variables, considered confusing 
factors, such as smoking, drinking alcohol and physical activity, were investigated.

Waist circumference was assessed by trained anthropometrists following technical measurement error criteria (7). After 12 hours fasting, blood samples were collected and plasma was separated to analyze triglycerides (TG) and glycemia with Labtest ${ }^{\circledR}$ products.

For determining life style parameters, it was standardized that a smoker had to smoke one cigarette, cigar or smoking pipe during the last 30 days before data collection (8). An alcoholic was categorized if drinking an alcoholic beverage at least once a year (9), and a sedentary was classified if not practicing physical activity at least three times a week for more than 45 minutes each session (10).

The LAP index was obtained using the formula proposed by Kahn: $\left(\mathrm{WC}_{(\mathrm{cm})}-58\right) \times \mathrm{TG}_{(\mathrm{mmol} / \mathrm{l})}(1)$.

The glucose blood levels and the LAP were divided in quartiles and, were evaluated by trend test. The association of glycemia and LAP was assessed by Pearson correlation and by linear regression adjusted by age (continuous) (model 1) and adjusted by age (continuous), physical activity (yes or no), smoking (yes or no) and alcohol intake (yes or no) (model 2). As a descriptive level $\mathrm{p}<0.05$ was considered for the test.

\section{RESULTS}

The fasting glucose blood levels increased together with the LAP quartiles ( $p$-trend=0.024), as shown in table 1 . There was a directly proportional correlation among LAP and fasting glycemia $(r=0.223 ; p=0.034)$. The variable dispersion may be visualized on graphic 1 .

After the modeling process, the LAP index explained the glycemia variation in $4.0 \%$, meaning that for each LAP unit, there is an increase of $0.317 \mathrm{mg} / \mathrm{dL}$ in gycemia. Adjusted by

\section{TABLE 1}

Fasting glucose blood levels distribution in female university students by LAP quartiles.

LAP (Quartile)

Glycemia

1

$(\mathrm{mg} / \mathrm{dl})$

$78.4(11.2)$
2

$75.0(11.0)$
3

$81.4(12.3)$ p-trend

4

$85.4(12.3)$

\section{GRAPHIC 1}

Dispersion Diagram relating fasting glycemia and LAP index in female university students.

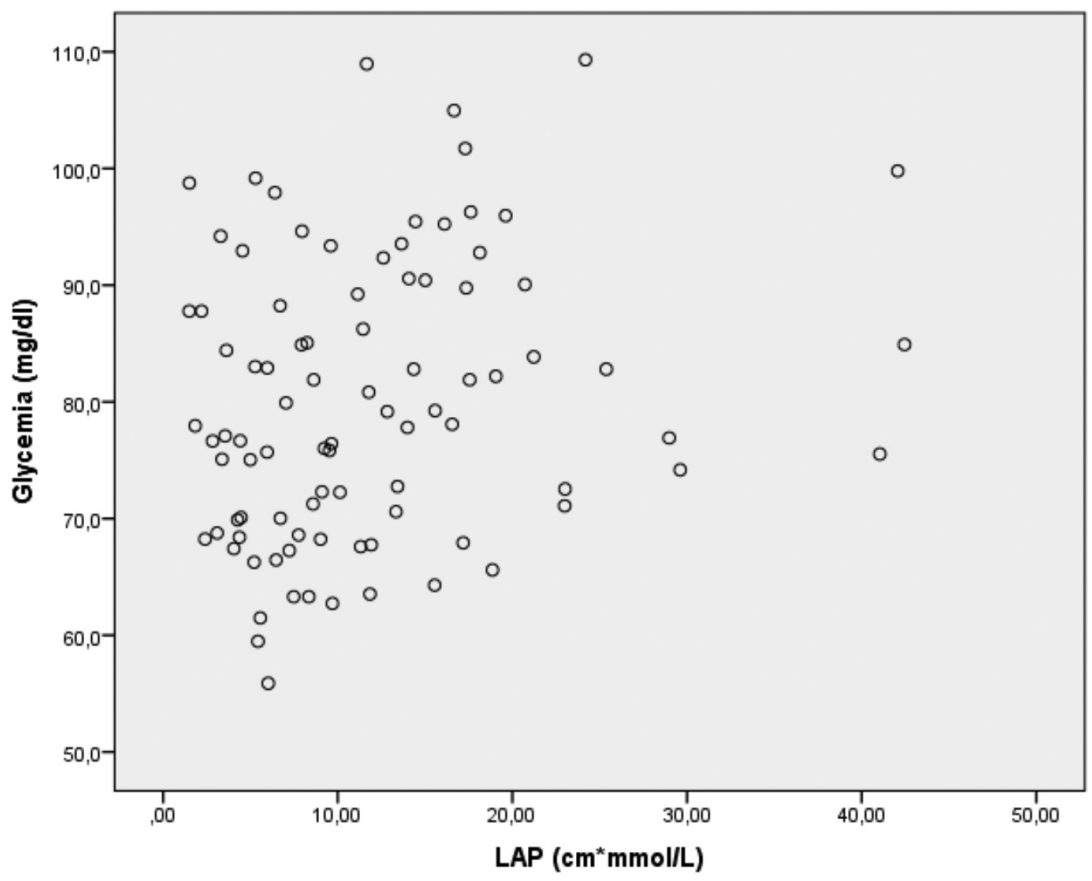


confusion factors (age, physical activity, smoking and alcohol drinking), the model didn't present significance (table 2).

\section{DISCUSSION}

The correlation found between LAP and glycemia in young female university students is positive and weak. The LAP explains the glycemia in $4 \%$ while other factors explain glycemia's levels.

The association between LAP and glucose regulation biomarkers has being described in literature and its results point out more accuracy of the index than body mass index (BMI) and other anthropometric parameters. Combining waist circumference with fasting triglycerides reflect, respectively, anatomic and physiological alterations associated to lipid accumulation. Thus, LAP might be used as a powerful index to predict insulin resistance in populations (6).

The only study we found which evaluated this association in young healthy female population was the one of Oh et al. (2). The research was developed with 2810 healthy female Koreans from 18 to 39 years of age. The authors defend the role of LAP in the early detection of individuals with abnormal regulation of glucose, metabolic syndrome or cardiovascular disease. Women with high LAP index and low BMI had higher glucose concentrations (after $2 \mathrm{~h}$ of $75 \mathrm{~g}$ overcharge of glucose) and higher insulin resistance than the ones who had high BMI and low LAP. Multiple logistic regression analysis showed that LAP exhibited higher odds ratio (OR) for abnormal glucose regulation than $\mathrm{BMI}(2)$.

Two different studies carried out in women with polycystic ovary syndrome (SOP), registered strong positive correlation between homeostasis model assessment (HOMA-IR) and LAP $(r=0,70 ; p<0,001)(3)$, as well as a significant association of increased LAP levels with elevated prevalence of glucose intolerance and metabolic complications, in both, SOP and controls (11). LAP also appeared to be superior to IMC and the relation waist-hips, considering OR for glucose intolerance (11).

LAP association with glucose metabolism biomarkers was also verified among adult participants, both sexes, at NHANES III. The results showed that LAP was very superior to IMC for identifying diabetic adults. The models with LAP were better to those with $\mathrm{BMI}$ to predict risk for the homeostasis model assessment (HOMA-IR) variables, such as fasting glycemia and glycated hemoglobin in individuals who didn't use insulin or hypoglycemiants (12).

It was observed in a study in China, with non diabetic individuals between 20 and 80 years of age, both sexes, that the HOMA-IR levels, fasting glycemia and glycemia after glucose overcharge increased with LAP quartiles $(p<0,001)$. Multivariate analysis showed that LAP had better impact over HOMA-IR than BMI and WC (6).

In another study carried out in Tehran, including men and non pregnant women older than 20 years, LAP presented higher OR for diabetes prevalence than BMI, WC and waist/hip factor, after adjustment for blood pressure and family history for diabetes. In older men, the OR for LAP was lower than the other anthropometric parameters and in young men the LAP was higher only for BMI. It was equal to the other indexes (4).

Literature has demonstrated the association of LAP with glucose metabolism alterations in different populations with varied statistical analysis. The results point out the efficacy of this index and its' superiority when compared with other indexes that only use anthropometric measurements. Some studies show efficacy between both sexes, but this is not completely clarified.

On the other hand, the need of calculating the LAP and the absence of cutoff lowers its applicability on screening of individuals at risk. Another aspect to consider is that the correlation between TG and glucose 13 and between WC and blood glucose 14 may suggest that the calculation of LAP wouldn't be an added advantage in predicting changes on glucose metabolism. However, there is also evidence showing that the combination of TG and WC is able to identify individuals with greater amount of visceral fat, which is an important risk factor for metabolic syndrome, diabetes and coronary artery disease $(2,3,11,12,15)$.

Our study's limitation was the evaluation of a unique glucose metabolism parameter (fasting glycemia), and an association with HOMA-IR was not performed or even a glucose overcharge test. Nevertheless, this is a good parameter because it is easy to obtain and it is not very expensive.

\section{CONCLUSION}

It is concluded that the Lipid Accumulation Product (LAP) is correlated with glycemia in female university students. Our findings reinforce previous studies that suggest association of LAP and glucose metabolism markers. LAP usage must be considered to follow up alterations in the glucose metabolism biomarkers in young women.

\section{RESUMEN}

La utilización de índices antropométricos para rastrear factores de riesgo cardiovascular y metabólico, ha sido de interés en varios estudios durante los últimos años. El Producto de Acumulación Lipídica (PAL) innova al combinar la circunferencia de cintura (CC), el cual es un parámetro antropométrico,

\section{TABLE 2}

Linear modeling between fasting glycemia (dependent variable) and LAP (independent variable) in university students.

\begin{tabular}{|c|c|c|c|}
\hline \multirow[t]{2}{*}{ LAP } & \multicolumn{3}{|c|}{ Glycemia } \\
\hline & Beta & $\mathrm{Cl} 95 \%$ & $\mathrm{R}^{2}$ \\
\hline Crude & 0,317 & 0,$024 ; 0,610$ & 0,039 \\
\hline Model $1^{*}$ & 0,278 & $-0,017 ; 0,573$ & 0,056 \\
\hline Model $2^{* *}$ & 0,231 & $-0,076 ; 0,538$ & 0,074 \\
\hline
\end{tabular}


con un parámetro bioquímico: los triglicéridos en ayunas. Kahn propuso el PAL el año 2005 como un índice mejor que el Índice de Masa Corporal (IMC) para predecir riesgo cardiovascular. Algunos estudios publicados no muestran el PAL en una población de mujeres jóvenes. Por esta razón, el objetivo del presente estudio fue analizar la asociación entre PAL y la glucemia en ayunas en estudiantes universitarias. Se detectó una correlación significativamente positiva, confirmando estudios previos en diferentes poblaciones.

Palabras clave: Glucemia, glucosa en sangre, producto de acumulación lipídica, estudiantes universitarias.

\section{BIBLIOGRAFÍA}

1. Kahn HS. The" lipid accumulation product" performs better than the body mass index for recognizing cardiovascular risk: a population-based comparison. BMC Cardiovasc Disord, 2005; p 5: 26.

2. Oh JY, Sung YA, Lee HJ. The lipid accumulation product as a useful index for identifying abnormal glucose regulation in young Korean women. Diab Medic 2013; 30(4): 436-42.

3. Wiltgen D, Benedetto IG, Mastella LS, Spritzer PM. Lipid accumulation product index: a reliable marker of cardiovascular risk in polycystic ovary syndrome. Human Reproduc. 2009; 24 (7): 1726-31.

4. Bozorgmanesh M, Hadaegh $F$, Azizi F. Predictive performances of lipid accumulation product vs. adiposity measures for cardiovascular diseases and all-cause mortality, 8.6-year follow-up: Tehran lipid and glucose study. Lipids Health Disease, 2010; 9(100): 1-13.

5. Diretrizes da Sociedade Brasileira de Diabetes 2009/Sociedade brasileira de diabetes. Itapevi, SP; A. Araújo Silva Farmacêutica. 2009; 3: 400.

6. Xia C, Li R, Zhang S, Gong L, Ren W, Wang Z, Li Q. Lipid accumulation product is a powerful index for recognizing insulin resistance in non-diabetic individuals. European $\mathrm{J}$ Clin Nutr, 2012; 66: 1035-8.
7. Norton $K$, Olds T, Albernaz NMF. Antropométrica: um livro sobre medidas corporais para o esporte e cursos da área de saúde. Porto Alegre: Artmed. 2005; 1: 389.

8. Centers Disease Control of Prevention [homepage na Internet]. Teen Smoking Rates Decline Significantly. Embargoed until Noon. May 16, 2002. Disponível em: http://www. cdc.gov/od/oc/media/pressrel/r020516.htm

9. Secretaria Nacional Antidrogas; Gabinete de Segurança Institucional. I Levantamento Nacional sobre os Padrões de Consumo de Álcool na População Brasileira. Brasília: Secretaria Nacional Antidrogas, 2007; p 1: 76.

10. Coelho VG, Caetano LF, Liberatore Júnior RDR, Cordeiro JA, Souza DRS. Perfil lipídico e fatores de risco para doenças cardiovasculares em estudantes de medicina. Arq Bras Cardiol. 2005; 85(1): 57-62.

11. Wehr E, Gruber HJ, Giuliani A, Moller R, Pieber TR, Obermayer-Pietsch $B$. The lipid accumulation product is associated with impaired glucose tolerance in PCOS women. J Clin Endocrinol Metab 2011; 96(6): E986-E90.

12. Kahn HS. The Lipid Accumulation Product Is Better Than $B M I$ for Identifying Diabetes A population-based comparison. Diabetes Care, 2006; 29(1): 151-3.

13. Yan Y, Deng H, Jian L, SuY, Li Y, Mi G. Associations of apolipoprotein A5 with triglyceride, adiponectin and insulin resistance in patients with impaired glucose regulation and type 2 diabetes mellitus. Int J Diabetes Dev Ctries, 2012; 33(1):13-7.

14. Gill JMR, Bhopal R, Douglas A, Wallia S, Bhopal R, Sheikh A, Forbes JF, McKnight J, Sattar N, Murray G, Lean MEJ, Wild SH. Sitting Time and Waist Circumference Are Associated With Glycemia in U.K. South Asians. Diabetes Care, 2011; 34: 1214-8.

15. Chiang $J K$, Koo M. Lipid accumulation product: a simple and accurate index for predicting metabolic syndrome in Taiwanese people aged 50 and over. BMC Cardiovascular Dis. 2012; $12: 78$. 